\title{
Surface tension and Curie temperature in ferroelectric nanowires and nanodots
}

\section{Wenhui Ma}

Published online: 16 July 2009

(C) Springer-Verlag 2009

\section{Erratum to: Appl Phys A}

DOI 10.1007/s00339-009-5246-7

There is a production error in Fig. 1, where an extra "mm" was mistakenly inserted during the production process at the publisher. The corrected Fig. 1 is given below.

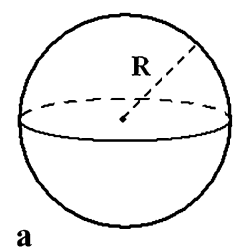

a
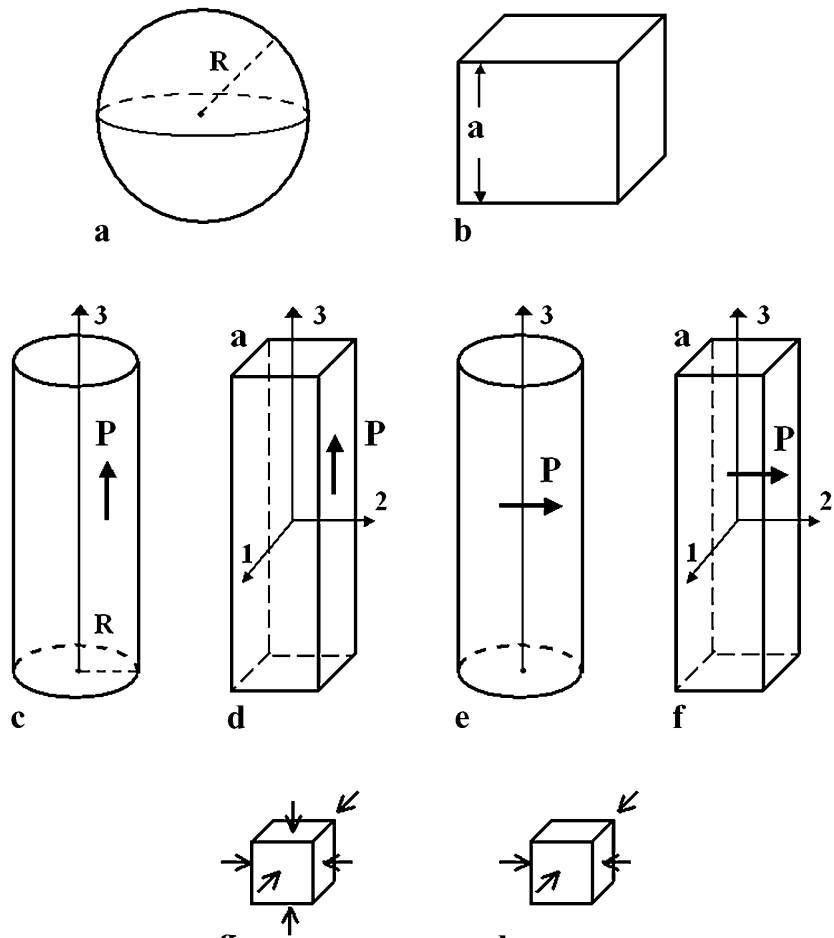

g

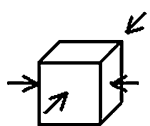

h

Fig. 1 Surface tension effect on ferroelectric nanocrystals. Orientation of polarization $P$ in nanodots and nanowires: (a) and (b) —arbitrary direction; (c) and (d) — parallel to the length axis; (e) and (f) - perpendicular to the length axis. The internal pressures in nanodots and nanowires are hydrostatic (g) and two-dimensional (h), respectively 